\title{
ATIK STRAFOR, ÇAY LİFi VE POLİSTİREN KÖPÜK KULLANILARAK SUDAKİ PETROL KİRLİLİĠiNİN GİDERİLMESİ
}

\author{
Meltem ÇUBUK*, Metin GÜRÜ ** , Ebru Lale UĞURLU ${ }^{* * *}$ \\ *Ulaştırma, Denizcilik ve Haberleşme Bakanlığı Emek, Ankara \\ ${ }^{* *}$ Gazi Üniversitesi Mühendislik Mimarlık Fakültesi, Kimya Müh. Böl. Maltepe, Ankara \\ ${ }^{* * *}$ Boru Hatları ile Petrol Taşıma A.Ș. Ümitköy, Ankara \\ $\underline{\text { melcubuk@yahoo.com, mguru@gazi.edu.tr, ebrulale27@gmail.com }}$
}

(Geliş/Received: 28.11.2013; Kabul/Accepted: 15.05.2014)

ÖZET

Sudaki petrol kirliliğinin temizlenmesinde yaygın olarak kullanılan emici malzemelerle ilgili yapılan bu çalışmada, adsorban malzeme olarak granül strafor, çay lifi ve polistiren köpük atıkları kullanılmış̧ır. Adsorban malzemelerin su ve tuzlu suda Adiyaman ve Kerkük petrollerini adsorplama kapasiteleri ASTM F726-06 standardına göre belirlenmiştir. Adsorban malzemelerin özgül yüzey alanları ise BET metodu ile belirlenmiş̧tir. Test sonucunda, her bir adsorbanın en yüksek özgül adsorpsiyon kapasitesinin 0,4 g'lık adsorban miktarında sağladığı görülmüştür. Adsorbanların Adıyaman ve Kerkük petrollerini özgül adsorplama kapasiteleri 24 saatlik test sonras1 sirasılyla, straforun 8,06 ve 5,32; çay lifinin 15,63 ve 13,16; polistiren köpüğün 41,46 ve 39,01 g adsorplanan petrol/g adsorban olarak bulunmuştur. Tuzlu suda ise Adıyaman ve Kerkük petrollerini sırasıyla; straforun 6,94 ve 4,40; çay lifinin 12,07 ve 11,54; polistiren köpüğün 35,21 ve $32,27 \mathrm{~g}$ adsorplanan petrol/g adsorban olarak adsorplayabildiği belirlenmiştir. Test sonuçlarına göre, yüzey alanı en büyük olan polistiren köpügün, çay lifi ve strafora göre özgül adsorpsiyon kapasitesinin daha yüksek olduğu tespit edilmiştir.

Anahtar Kelimeler: Petrol kirliliği, sorpsiyon, strafor, çay lifi, polistiren köpük

\section{CLEANING UP OIL SPILLS ON WATER SURFACE WITH WASTES OF GRANULAR STYROFOAM, TEA FIBERS AND POLYSTYRENE FOAM}

\begin{abstract}
In this study performed about the absorbent materials commonly used in cleaning up oil spills on water surface, wastes of granular styrofoam, tea fibers and polystyrene foam were used as adsorbent materials. The capacities of adsorbents on adsorbing oils of Adıyaman and Kerkük in water and in salty water have been determined based on the ASTM F726-06 method. The specific surface areas have been identified based on the BET method. According to the results of the test, the highest specific adsorption capacity of each adsorbent has been provided within $0.4 \mathrm{~g}$ amount of adsorbents. According to the test duration of 24 hours, the specific adsorption capacities of adsorbents for the oils of Adiyaman and Kerkük, were determined as 8.06 and $5.32 \mathrm{~g}$ of adsorbed oil/g adsorbent for styrofoam, 15.63 and 13.16 for tea fiber and 41.46 and 39.01 for polystyrene foam respectively. As far as the salty water conditions are concerned, specific adsorption capacities of adsorbents for the oils of Adiyaman and Kerkük were determined as 6.94 and $4.40 \mathrm{~g}$ of adsorbed oil/g adsorbent for styrofoam, 12.07 and 11.54 for tea fiber and 35.21 and 32.27 for polystyrene foam respectively. According to results of the tests, the specific adsorption capacity of polystyrene foam having the the largest surface area was determined higher than the specific adsorption capacities of granular styrofoam and tea fiber.
\end{abstract}

Keywords: Oil pollution, sorption, styrofoam, tea fiber, polystyrene foam 


\section{GIiRIŞ̧ (INTRODUCTION)}

Dünya deniz ticaret hacminin her geçen yıl artması, beraberinde petrol taşımacıllğında yaşanabilecek tanker kazalarının, dolayısıyla kirlilik boyutlarının artmasına yol açmıştır. Bir tanker kazası sonucunda oluşan petrol kirliliğginin yaratmış olduğu çevresel etkinin büyüklüğ̈̈, temizlik faaliyetlerinin zorluğu ve maliyetinin yüksekliği geçmişte yaşanmış kazalardan açıkça görülmektedir. Mevcut istatistikler, genel olarak tanker kazalarında denize dökülen petrol miktarının kaza başına ortalama 8175 ton olduğunu, tankerin batma durumunda ise ortalama 6790 ton petrolün denize yayıldığını göstermektedir. Avrupa istatistiklerine göre bir ton petrolün temizlenmesinin maliyetinin 2005 y1l verileriyle 10807 ABD doları olduğu belirtilmektedir. Ağır petrol, hafif petrolden daha yüksek maliyetlerle temizlenebilmekte, genellikle denize yayılan petrolün \%10-20'si geri kazanılabilmektedir. Kaybedilen petrolün her varilinin 130-150 ABD doları arasında bir değeri olduğu da dikkate alındığında, bir kaza halinde milyonlarca dolarlık maliyet ortaya çıkmaktadır.

Olas1 petrol döküntülerine, mümkün olan en kisa süre içerisinde müdahale edilmesi, yayılmasının önlenmesi ve toplanması, sorunun daha fazla büyümeden çözülmesi hususunda önemli bir adımdır. Müdahale yönteminde petrol bariyerleri ile petrol döküntüsünün yayılmasının önlenmesi ve sonra da siyırıcilar vasitasıyla petrolün toplanarak temizlenmesi tercih edilmektedir. Sahillerde, dar koylarda, nehirlerde ve petrolün enkaz parçalarıyla karıştı̆g 1 durumlarda ise temizleme işlemi için emici malzemelerden (sorbentler) yararlanılmaktadır.

Günümüz teknolojisinde, yüzen petrol tabakalarının küçük olması, sığ sular ya da sızıntı kaynağına ulaşamama gibi durumlarda, petrol döküntülerinin toplanmasında ve ortamdan giderilmesinde yüksek yă emme ve tutma kapasitelerine sahip suni veya doğal sorbent malzemeler yaygın olarak kullanılmaktadır. Petrol döküntülerinin temizlenmesinde araştırmacılar tarafından çeşitli sorbentler üzerinde çalışmalar yapılmıştır. Bu çalışmalarda, yaprak küspesi, karışık testere talaşı, kenevir, hindistan cevizi lifi, sünger-kabak, ham ipek lifleri, sol jeller ve pamuk otu lifi gibi malzemeler kullanılarak bunların petrolü adsorbe/absorbe etme kabiliyetleri/kapasiteleri belirlenmeye çalışılmıştır. Liflerin petrol emme kapasiteleri eğilimi; ham ipek lifi $>$ kenevir ve testere talaşı >hindistan cevizi lifi $>$ sünger-kabak $>$ yaprak küspesi olarak tespit edilmiştir. Ham ipek lifinin, yüksek hidrofobik derecesi ve düşük su çekimi nedeniyle hızlı ve çok yüksek kapasitede petrol emme özelliği gösterdiği (yaklaşık 85 g petrol/g - 24 saatte) diğer taraftan, kenevir, sünger-kabak ve testere talaşının, su-yağ döküntüsü ortamında yetersiz olduğu bildirilmiştir [1].
Sentezlenen yüksek gözenekli, düşük yoğunluklu ve hidrofobik aerojellerin ağırlıklarının 237 katı petrol emebildikleri raporlanmıştır [2]. Sorbent malzeme olarak organik kil, ham pamuk elyafi ve ince kum kullanılan çalışmada, emici malzemelerin mikro gözeneklerde adsorpsiyon süreci için düşük yüzey alanına ve sınırlı gözenek hacmine sahip oldukları, elyaf malzemede ana adsorpsiyon mekanizmasının elyaf yüzeyinde değil elyaflar arasındaki kılcal borularda gerçekleştiği kanaatine varıldığı belirtilmiştir. Organik kilin nispeten hidrofobik, pamuk elyafının ise tamamen hidrofobik olduğu, ayrıca, pamuk elyafının, hidrofobik olması, iyi hidrokarbon afinitesi, temas anında hizlı emme ve elyaflar arasındaki kılcal borucuklarla hızlı emme ve tutma gibi birçok önemli özelliğe sahip ve uygun sorbent malzeme olduğu sonucuna varıldığı bildirilmektedir [3].

Araştırmacılar her türlü pamuk otu lifinin her türlü sentetik pamuk otu malzemeye göre daha fazla ve daha hızlı yağı absorbe ettiği ve hiçbir sorbentin gözlemlenebilir miktarda suyu absorbe etmediği saptanmıştır [4]. Adsorban olarak yüksek kalsiyum içerikli uçucu külün kullanıldığı çalışmada ise uçucu külün suda yüzebilme özelliğinin iyileştirilmesi için sodyum oleat ile modifiye edilmiştir. Çalışmada uçucu külün iyi bir petrol emilim davranışı sergilediği ancak, uçucu külün su yüzeyinde kalabilme yeteneğinin kazandırılması için modifiye edilmesi gerektiği, bu modifikasyon işleminin ise emme kapasitesine etkisi olmadığı saptanmıştır [5].

Bir başka deneysel çalışmada, doğası gereği hidrofilik özelliğe ve gözenekli yapıya sahip çöktürülmüş kalsiyum karbonat tozuna hidrofobik özellik kazandırılabilmesi için stearik asit ile muamele edildiği raporlanmıştır. Süper hidrofobik numunelerin su-mazot karışımında mazotu seçerek emdiği ve geriye berrak bir su kaldığının gözlemlendiği bildirilmektedir [6]. Genleştirilmiş üç tür perlit, polipropilen ve selülozik malzemelerin petrol emme kapasitelerinin araştırıldığı çalışmada da, yaş (su ve petrol) ortamda en iyi performans1 polipropilen ve selülozik elyafın gösterdiği ve gerek dökülen petrolün temizlenmesi işlemlerinde, gerekse atık sulardaki organik moleküllerin temizlenmesinde, ticari sentetik emici maddelerin bir kısmının yerine doğal sorbent mineral malzemelerin kullanılabileceği rapor edilmiştir [7].

Bu çalışma ile ilk defa, literatürde özgül adsorpsiyon kapasiteleri bulunmayan; atık granül straforun, atık çay lifinin ve yerleşik köpük paketleme sistemlerinde kullanılan polistiren köpük atığının, ASTM F726-06 (Adsorbanların Sorbent Performansı Standart Test Metodu) da yer alan kısa ve uzun süreli test metotları esas alınarak özgül adsorpsiyon kapasitelerinin belirlenmesi amaçlanmıştır. 


\section{MATERYAL VE METOT (MATERIAL AND METHOD)}

$\mathrm{Bu}$ çalışmada; adsorban malzeme olarak strafor plakaların kesimi sırasında oluşan ve geri kazanılamayan atık durumundaki granül strafor, ülkemiz Doğu Karadeniz Bölgesi çay fabrikası atı̆̆ olan atık çay lifleri ve yerleşik köpük paketleme sistemlerinde kullanılan polistiren köpük atığ kullanılarak petrolü adsorplama kapasiteleri araştırılmıştır. Tablo 1'de adsorban malzemelerin yoğunlukları verilmiştir. Petrol örnekleri olarak Adıyaman ve Kerkük ham petrolü seçilmiştir. Çalışmalar, ASTM F726-06 (Adsorbanların Sorbent Performansı Standart Test Metodu)'na göre yürütülmüştür. Tablo 2'de deneysel çalışmada kullanılan petrolün özellikleri verilmiştir.

Tablo 1. Adsorban malzemelerin yoğunluğu (density of adsorbent materials)

\begin{tabular}{ll}
\hline Adsorban & Yoğunluk $\left(\mathrm{g} / \mathrm{cm}^{3}\right)$ \\
\hline Strafor & 0,528 \\
Çay lifi & 0,433 \\
Polistiren köpük & 0,302 \\
\hline
\end{tabular}

Tablo 2. Adıyaman ve Kerkük ham petrollerinin özellikleri (Spesification of oils of Adiyaman and Kerkük)

\begin{tabular}{lll}
\hline Özellik & $\begin{array}{l}\text { Adıyaman } \\
\text { Petrolü }\end{array}$ & $\begin{array}{l}\text { Kerkük } \\
\text { Petrolü }\end{array}$ \\
\hline API gravite & 26,70 & 34 \\
Özgül Ağırlık $\left(\mathrm{g} / \mathrm{cm}^{3}\right)$ & 0,894 & 0,845 \\
Viskozite $\left(20^{\circ} \mathrm{C}, \mathrm{cSt}\right)$ & 8,70 & 7,50 \\
Asfalten $(\%)$ & $5,50-34,70$ & $4,50-29,20$ \\
$\mathrm{H}_{2} \mathrm{~S}$ Oranı $(\%)$ & $1,24-1,90$ & 2,10 \\
\hline
\end{tabular}

Adsorbanların yüzey alanları, BET yöntemi ile gazların gözenekli katı malzemelerin yüzeyinde gösterdikleri fiziksel adsorpsiyon karakteristiklerinden faydalanılarak belirlenmiştir. Adsorban malzemelerin yüzey alanlarının belirlenmesinde Nova Quantochrome 2200-E model yüzey alanı ölçüm cihazı kullanılmıştır. BET yüzey alanı, farklı relatif basınçlarda $(0,05-0,90$ arası) ölçülmüş ve BET izotermine göre yüzey alan değerleri hesaplanmıştır. Testlerden önce adsorban malzemeler, hassas ölçüm yapılabilmesi için sıcaklığ 1 $110{ }^{\circ} \mathrm{C}$ 'ye ayarlanmış etüvde 24 saat bekletilmiştir. Sonrasında adsorban numuneler içerisindeki gözenekleri tıkamış olan su buharı vb. safsızlıkların giderilebilmesini teminen vakum altında $50{ }^{\circ} \mathrm{C}$ 'da 1 saat süreyle gaz giderme işlemi (degasing) uygulanmıştır. Adsorplanan gaz olarak $\mathrm{N}_{2}$ gazı kullanılmıştır.

Petrolü adsorplama kapasitelerinin belirlenmesi amaciyla yapılan deneyler ASTM F726-06 standardına göre gerçekleştirilmiş ve sıcaklığ $23 \pm 4$ ${ }^{\circ} \mathrm{C}$ 'a ve karıștırma hızı 150 devir/dakika'ya ayarlanmış su banyosundan oluşan proses kullanılmıştır. Numuneler kısa (short) test için 15 dakika, uzun (long) test için 24 saat su banyosunda tutulduktan sonra örgü sepette $30 \mathrm{~s}$ süzülmüş ve tartımları 0,1 mg'a duyarlı terazi ile yapılarak hesaplamalara geçilmiştir. Her bir test üç kez tekrarlanmış ve üç testin aritmetik ortalaması alınmıştır. \%15'den fazla sapma gösteren test sonuçları iptal edilmiş ve testler tekrarlanmıştır.

\section{SONUÇLAR VE TARTIŞMA (RESULTS AND DISCUSSION)}

Adsorban malzemelerin BET metoduyla elde edilen yüzey alanı değerleri Tablo 3'de verilmiştir.

Tablo 3. Adsorban malzemelerin yüzey alanı değerleri (Values surface area of adsorbent materials)

\begin{tabular}{ll}
\hline Adsorban & Yüzey Alanı $\left(\mathrm{m}^{2} / \mathrm{g}\right)$ \\
\hline Strafor & 461,31 \\
Çay lifi & 472,75 \\
Polistiren köpük & 576,87 \\
\hline
\end{tabular}

Tablo 3 incelendiğinde en yüksek yüzey alanına sahip adsorbanın polistiren köpük olduğu görülmektedir. Adsorban malzemelerin yüzey alanı arttıkça gözenek çapının düşmesi, yoğunluğu arttıkça yüzey alanının düşük olması beklenmektedir. Adsorpsiyon olayı, adsorbanın yüzeyinde gerçekleştiği için adsorpsiyon kapasitesi yüzey alanı ile orantılıdır. Adsorplayıcının partikül boyutunun küçük, yüzey alanının geniş ve gözenekli yapıda olması adsorpsiyonu artıracaktır [8, 9]. Bu nedenle polistiren köpük ile yapılan testlerin daha iyi sonuç vereceği beklenmektedir.

Diğer taraftan adsorpsiyon işleminde yüksek oranda mezo (orta) ve mikro (küçük) gözenekler tercih edildiği ve mezo gözeneklerin organik bileşiklerin adsorpsiyonunda önemli gözenek grubu olduğu bilinmektedir [10]. Dolayısıyla adsorbanın yüzey alanının büyük olması, daha küçük gözenek yapısına sahip olduğunu ve adsorpsiyon işlemi için uygun olduğunu göstermektedir.

ASTM F726-06 test standardına göre yapılan su adsoplama test sonuçları Tablo 4'de verilmiştir. Üç tür adsorban malzemenin özgül su adsorplama kapasitelerinde büyük farklılıklar olduğu belirlenmiştir.

Aynı miktar adsorbanların su adsorplama kapasiteleri karşılaştırıldığında straforun en düşük, polistiren köpüğün ise en yüksek su adsorplama kapasitesine sahip olduğu tespit edilmiştir. $\mathrm{Bu}$ durum adsorbanların hidrofilik yapıda olduklarını ve petrol ile birlikte suyu da yüksek oranda adsorplayacağını göstermektedir. Adsorban malzemelerin araştırıldığ çalışmalarda genellikle hidrofobik malzemeler tercih edilmiş veya hidrofilik malzemelere hidrofobik 
özellik kazandırılmaya çalışılmış olmakla birlikte, nispeten hidrofilik özelliğe sahip selülozik elyaf ve organik kil gibi bazı organik malzemelerle de çalışmalar yapılmıştır $[3,7]$.

Tablo 4. Adsorban malzemelerin özgül su adsorplama kapasiteleri (Specific water adsorption capacity of adsorbent materials)

\begin{tabular}{|l|c|c|}
\hline $\begin{array}{c}\text { Adsorban } \\
\text { Malzeme } \\
\left(\mathrm{S}_{0}=0,4 \mathrm{~g}\right)\end{array}$ & $\begin{array}{c}\text { Test Sonucu } \\
(\text { Ort.) } \\
\left(\mathrm{S}_{\mathrm{WT}}\right),(\mathrm{g})\end{array}$ & $\begin{array}{c}\text { Özgül Su Adsorplama } \\
\text { Kapasitesi } \\
\mathrm{S}_{\mathrm{WA}}=\left(\mathrm{S}_{\mathrm{WT}}-\mathrm{S}_{0}\right) / \mathrm{S}_{0} \\
(\mathrm{~g} \mathrm{su} / \mathrm{g} \text { adsorban })\end{array}$ \\
\hline Strafor & 1,68 & 3,19 \\
\hline Çay lifi & 3,67 & 8,18 \\
\hline Polistiren köpük & 12,52 & 30,30 \\
\hline
\end{tabular}

Burada;

$\mathrm{S}_{0}$ : Test öncesi adsorban ağırlığ1

$\mathrm{S}_{\mathrm{WT}}$ : Test sonrası adsorban ağırlığ

$\mathrm{S}_{\mathrm{WA}}$ : Özgül adsorplama kapasitesi

Adsorbanların petrol adsorplama test sonuçlarından elde edilen verilere göre oluşturulan ve adsorban miktarına bağlı olarak özgül adsorplama kapasitelerini veren Şekil 1 incelendiğinde adsorban miktarı arttıkça petrol adsorplama kapasitesinin azaldığ 1 ve ASTM F726-06 metoduna göre alınabilecek en küçük adsorban miktarında en yüksek adsorpsiyonun sağlandığı görülmektedir. Diğer taraftan, adsorban olarak kullanılan granül straforun, çay lifinin ve polistiren köpüğün atık malzeme olmaları, hem bu atık malzemelerin değerlendirilmesinde, hem de çok yüksek maliyetlere sebep olan petrol kirliliklerinin giderilmesinde temizleme sorbentleri olarak kullanılabilmelerine imkan sağlayacaktır.

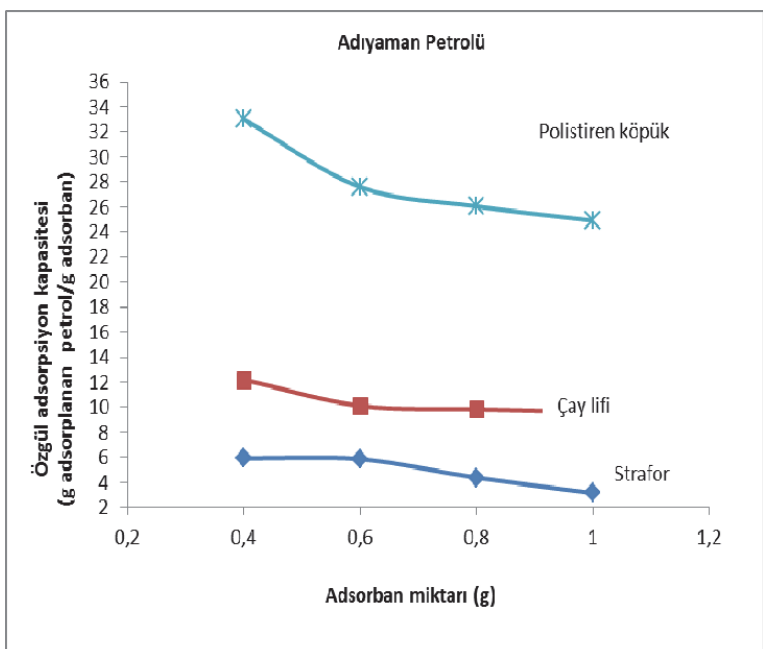

Şekil 1. Kısa süreli test; adsorban miktarına bağlı Adıyaman petrolünün adsorplanma değişimi (Shortterm test; Variation of adsorbed Adiyaman's oil as a function on the amount of adsorbent)

Adsorbanların petrol adsorplama eğilimleri, testler sırasında da gözle görülür şekilde tespit edilebilmiştir (Şekil 2). Özellikle de süzme sularına dikkat edildiğinde polistiren köpükten, oldukça temiz bir süzme suyu elde edilmiştir (Şekil 3). Çay lifi süzme suyunun diğerlerinden renk olarak koyu elde edilmesinin nedeni çayın suya renk verme özelliğinden kaynaklanmaktadır.

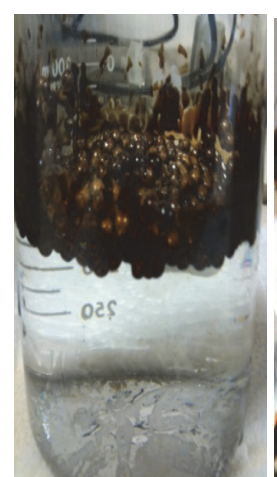

(a)

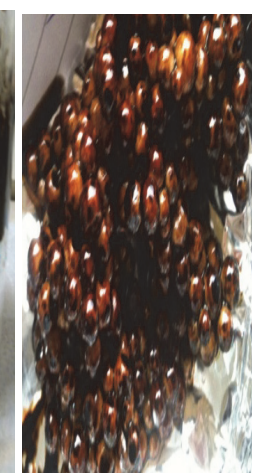

(b)

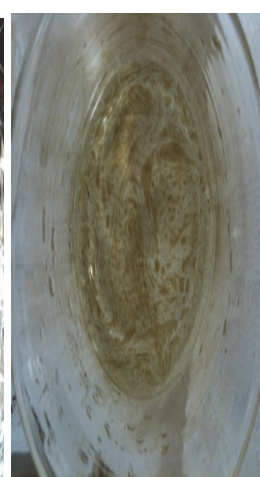

(c)

Strafor

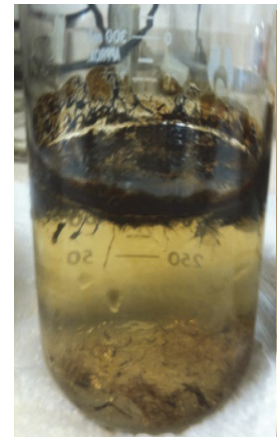

(a)

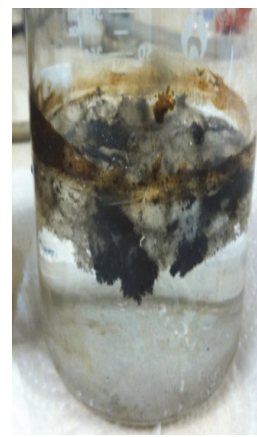

(a)

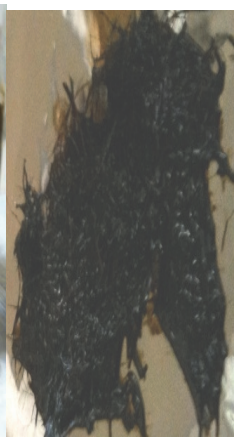

(b)

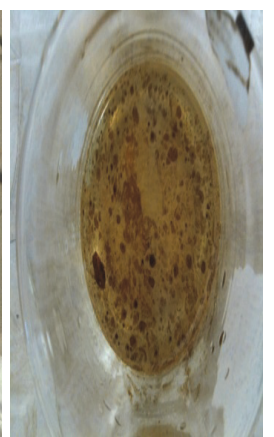

(c)

\section{Çay lifi}

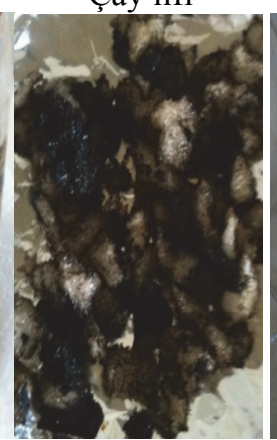

(b)

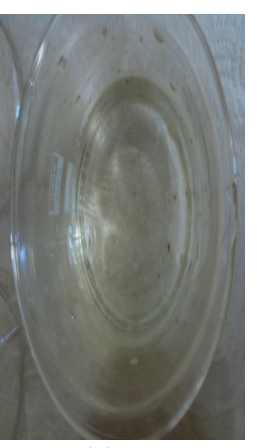

(c)

Polistiren köpük

Şekil 2. Adıyaman petrolü kısa süreli test görüntüleri; (a) süzme öncesi, (b) kalıntı, (c) süzüntü (Short-term test images of Adiyaman's oil; (a) before filtering, (b) residue (c) filtrate)

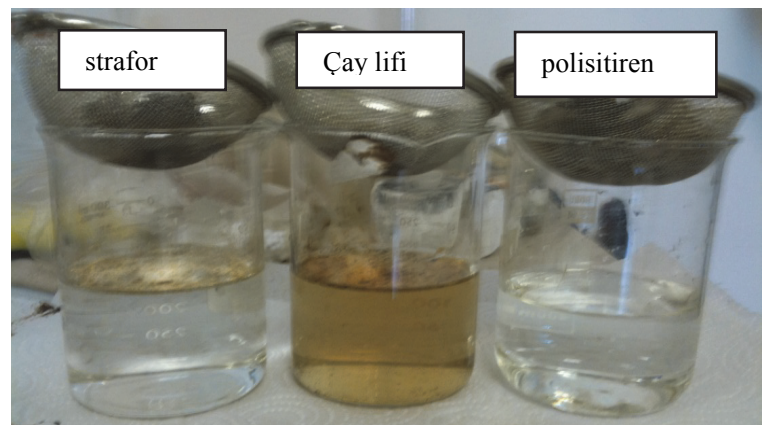

Şekil 3. Kısa süreli test sonucu; Adıyaman petrolünün süzme suları (Short-term test result; filtrate of Adıyaman's oil) 
Kerkük petrolü kullanılarak gerçekleştirilen deneysel çalışmalarda elde edilen verilere göre yapılan hesaplamalar sonucunda belirlenen adsorban malzemelerin özgül adsorpsiyon kapasitelerine ait grafik Şekil 4'de yer almaktadır.

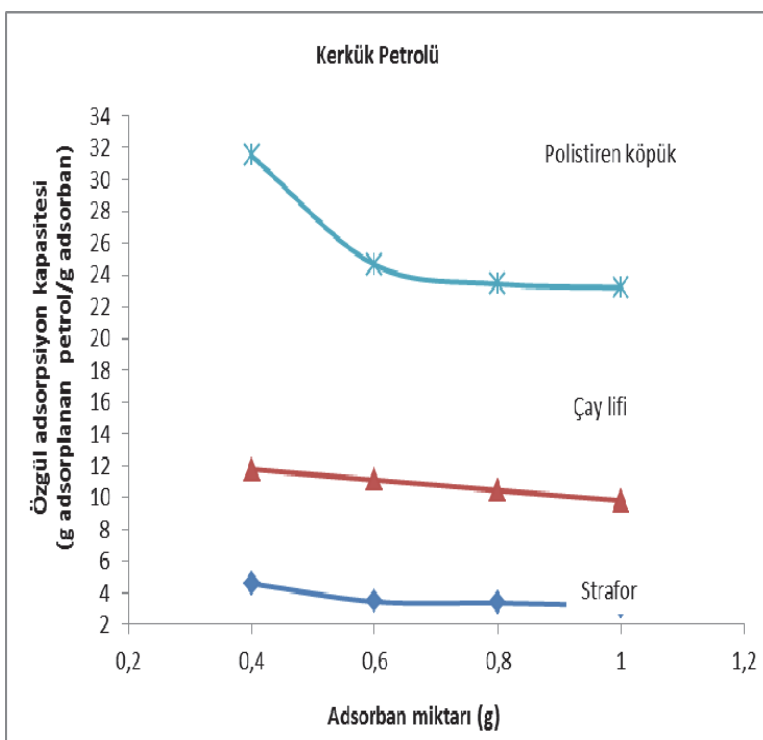

Şekil 4. Kısa süreli test; adsorban miktarına bağlı Kerkük petrolünün adsorplanma değişimi (Short-term test; Variation of adsorbed Kerkük's oil as a function on the amount of adsorbent)

Veriler incelendiğinde adsorbanların Kerkük petrolünü, Adryaman petrolüne göre nispeten düşük oranda adsorpladığı görülmektedir. $\mathrm{Bu}$ durumun, Kerkük petrolünün viskozitesinin düşük ve dolayısıyla daha fazla uçucu bileşenlere sahip olmasından kaynaklandığı düşünülmektedir. Düşük yoğunluklu petroller suyun üzerinde yüzdükleri gibi düşük viskoziteye de sahiptirler ve uçucu bileşenleri fazladır [11]. Yine de adsorbanların Kerkük petrolünü de çok iyi bir şekilde adsorpladığı tespit edilmiştir (Şekil 5).

Kısa süreli (short) test metodu sonucunda maksimum adsorpsiyonun sağlandığı adsorban miktarları ile ASTM F726-06 standardı çerçevesinde uzun süreli (long) test metoduna geçilmiştir. 24 saat içerisinde petrolün bünyesindeki uçucu bileşenlerin ayrılacağ bilinmektedir [11]. 24 saatlik test sonucunda elde edilen veriler incelendiğinde (Şekil 6) kısa süreli (short) test neticesinde elde edilen sonuçlara benzer sonuçların elde edildiği görülmektedir. Yine, polistiren köpükten ve Adryaman petrolünden en iyi sonuçlar elde edilmiştir.

Diğer taraftan petrolün viskozitesi arttıkça, malzeme gözeneklerine emilme hızı düşer gibi görünse de, süzülürken malzemenin yüzeyine yapışma ve gözeneklerinde kalma özelliğini arttırması [7], Adıyaman petrolünün Kerkük petrolüne nazaran kısmen daha fazla emildiğini düşündürmektedir. Düşük viskoziteli Kerkük petrolü, sudan çıkarılırken ve süzülürken adsorban malzemeden salınmış ve emilimi azalmıştır.

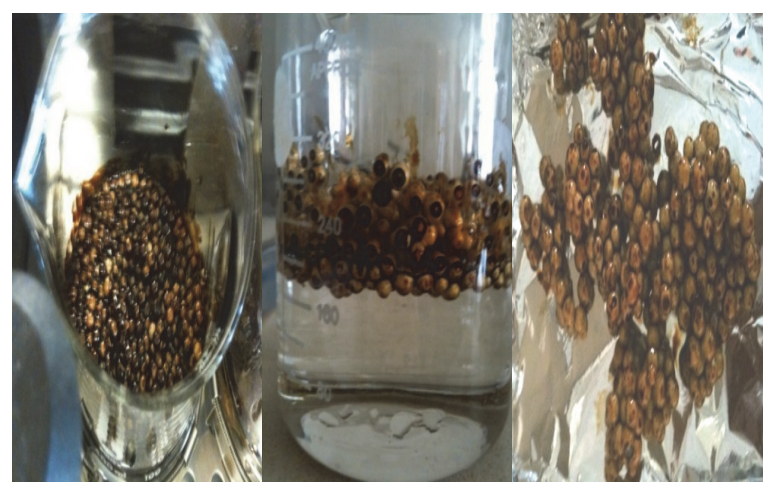

(a)

(b)

(c)

Strafor

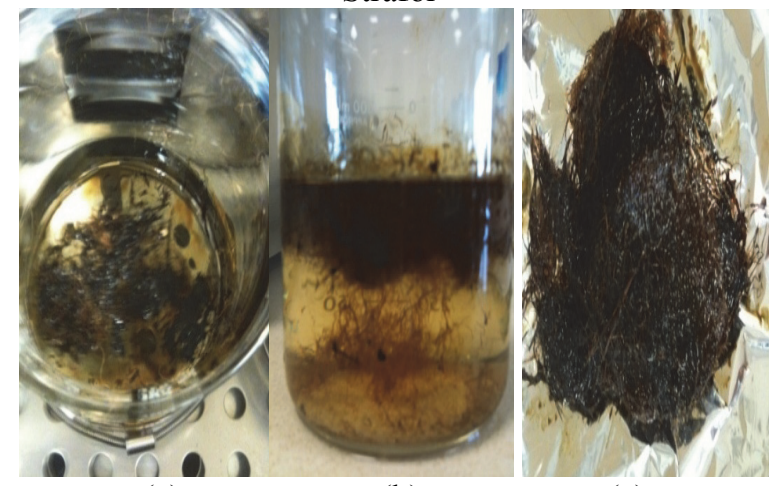

(a)

(b)

(c)

Cay lifi

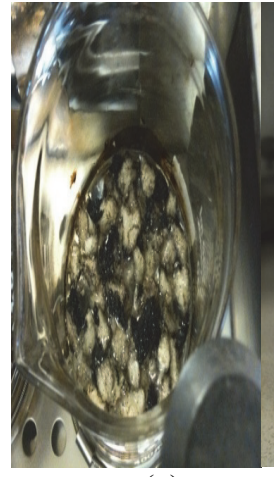

(a)

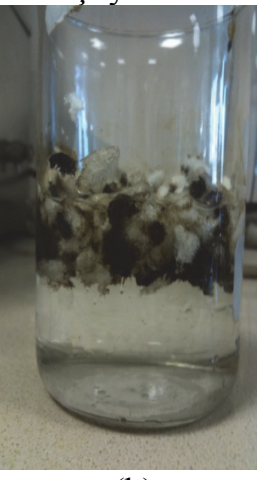

(b)

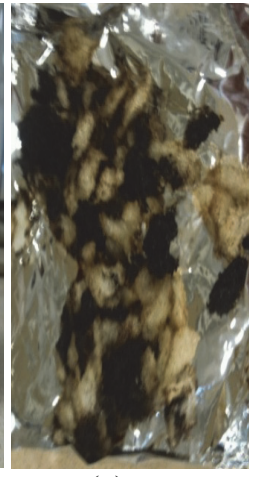

(c)
Polistiren köpük

Şekil 5. Kerkük petrolü kısa süreli test görüntüleri; (a) test sonrası, (b) süzme öncesi, (c) kalıntı (Short-term test images of Kerkük's oil; (a) After test, (b) before filtering (c) residue)

Adsorban malzemelerin tuzlu suda adsorpsiyon kapasitelerini belirlemek amaciyla kütlece \%3 $\mathrm{NaCl}$ içeren su numuneleri üzerine tatlı suda en yüksek adsorpsiyonun elde edildiği adsorban malzeme miktarı ilave edilmiş ve ASTM F726-06 standardında yer alan hesaplama yöntemi ile önce tuzlu su adsorplama kapasiteleri (Tablo 5) sonrasinda kısa (short) ve uzun (long) test yöntemine göre petrol adsorplama kapasiteleri hesaplanmıştır. 


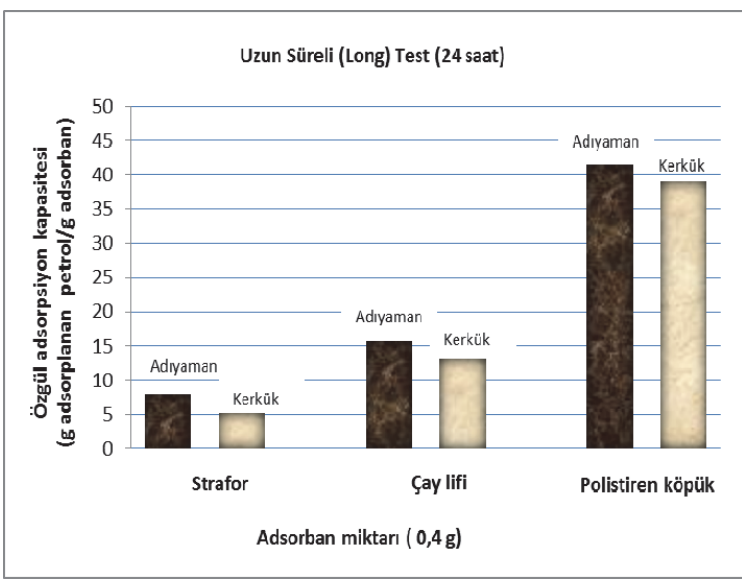

Şekil 6. Uzun süreli test; adsorban malzemelerin petrol özgül adsorpsiyon kapasiteleri (Long-term test; specific oil adsorption capability of adsorbent materials)

Deneysel çalışmalar sonucunda üç tür adsorban malzemenin de tuzlu suyu adsorplama kapasitelerinin, tatlı su adsorplama kapasitelerinden düşük olduğu görülmüştür.

Tablo 5. Adsorban malzemelerin tuzlu su adsorplama değerleri (Salty water adsorption capacity of adsorbent materials)

\begin{tabular}{|l|c|c|}
\hline $\begin{array}{c}\text { Adsorban } \\
\text { Malzeme } \\
\left(\mathrm{S}_{0}=0,4 \mathrm{~g}\right)\end{array}$ & $\begin{array}{c}\text { Test } \\
\text { Sonucu } \\
(\text { Ort. }) \\
\left(\mathrm{S}_{\mathrm{WT}}\right),(\mathrm{g})\end{array}$ & $\begin{array}{c}\text { Tuzlu Su Özgül Adsorpsiyon } \\
\text { Kapasitesi } \\
\mathrm{S}_{\mathrm{WA}}=\left(\mathrm{S}_{\mathrm{WT}}-\mathrm{S}_{0}\right) / \mathrm{S}_{0} \\
(\mathrm{~g} \text { tuzlu su/g adsorban })\end{array}$ \\
\hline Strafor & 1,39 & 2,48 \\
\hline Çay lifi & 3,37 & 7,41 \\
\hline Polistiren köpük & 11,82 & 28,56 \\
\hline
\end{tabular}

Tuzlu suyun emiliminin düşük olması, tuzun suyun yoğunluğunu ve iyon yükünü arttırmış olmasından ve yoğunluğu artan sıvının adsorban malzemelerin gözeneklerine hareketinin yavaşlamasından kaynaklandığı düşünülmektedir. Nitekim, çözeltideki iyon yükünün artmasının adsorpsiyon hızını düşürdüğü tespit edilmiştir [12].

Kütlece \%3'lük $\mathrm{NaCl}$ içeren su numunesi ve kısa süreli (short) test metoduna göre petrol özgül adsorpsiyon kapasiteleri Şekil 7'de verilmiştir. Petrol adsorpsiyonun tatlı suda elde edilen değerlerden kısmen düşük olduğu görülmektedir. Adsorban malzemelerin tuzlu su adsorplama kabiliyetlerinin tatlı suya göre düşük, petrol adsorplama kabiliyetlerinin de tatlı suya göre kısmen düşük olması, sudaki iyon yükünün artışı ve adsorban malzemelerin suyu adsorplama hızını düşürmesinden kaynaklanmaktadır [12]. Bu durumda adsorban malzemelerin denizde petrol kaynaklı kirliliklerde kullanılması tatlı suya nazaran daha elverişli olacaktır.

Literatürde konu ile ilgili çalışmalarda, deniz suyunu simüle edebilmek için yapay okyanus suyu veya $\mathrm{NaCl}$ içeren su kullanılmıştır [5, 13]. Petrol adsorpsiyon kapasitesinin, ASTM F726-06 standardına göre belirlenmesine yönelik çalışmalarda genellikle adsorban malzemelerin hidrofobik özellikleri ön plana çıkmıştır. Ancak, organik kil gibi tam hidrofobik olmayan malzemelerle de çalışılmış ve ham pamuk elyafına yakın sonuçlar elde edilmiştir [3].

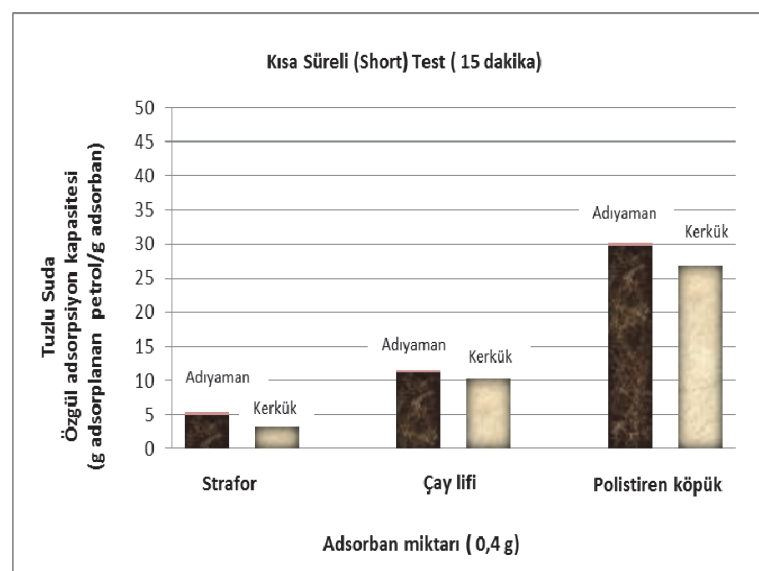

Şekil 7. Kısa süreli test; adsorban malzemelerin tuzlu suda petrol özgül adsorpsiyon kapasiteleri (Short-term test; specific oil adsorption capability of adsorbent materials in salty water)

Kütlece \%3'lük $\mathrm{NaCl}$ içeren su numunesi ile uzun süreli (long) test sonucuna göre adsorbanların özgül adsorpsiyon kapasiteleri (Şekil 8), kısa süreli (short) test metodundan daha fazla olduğu tespit edilmiştir. Şekil 8 incelendiğinde Adıyaman petrolü ile Kerkük petrolünün adsorpsiyonu arasında çok fazla bir fark olmadığı görülmektedir. Değerlerin tatlı su ile yapılan çalışma sonuçlarından kısmen düşük olması ise sudaki iyon yükünün artışı ve adsorpsiyon hızının düşmesi ile açıklanabilmiştir [12].

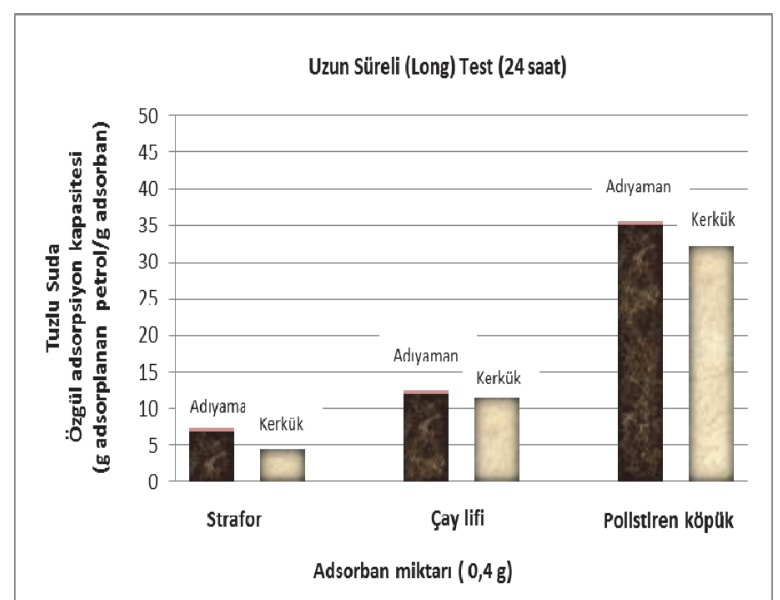

Şekil 8. Uzun süreli test; adsorban malzemelerin tuzlu suda petrol özgül adsorpsiyon kapasiteleri (Long-term test; specific oil adsorption capability of adsorbent materials in salty water)

Kütlece $\% 3 \mathrm{NaCl}$ içeren tuzlu suda 24 saatlik süre sonunda strafor, çay lifi, polistiren köpük Adıyaman petrolü-su karışımlarını sırasıyla ağırlıklarının yaklaşık 7, 12 ve 35 katı adsorplamıştır. Kerkük 
petrolü-su karışımını ise sırasıyla ağırlıklarının yaklaşık 4, 12 ve 32 katı adsorpladığı tespit edilmiştir. Pamuk otu ile yapılan çalışmada pamuk otunun ağırlığının 1,5 katı petrolü adsorpladığı rapor edilmiştir [4].

\section{SONUCLARIN DEĞERLENDİRILMESI (CONCLUSION)}

ASTM F726-06 test metoduna göre yapılan deneyler neticesinde, en yüksek adsorpsiyon, tüm adsorban malzemeler için 0,4 g adsorban miktarı ile elde edilmiştir. Adsorban malzemelerden granül straforun, strafor plakaların kesimi sırasında oluşan ve geri kazanılamayan atık malzeme olması, çay liflerinin çay fabrikalarının atık malzemesi olması, endüstride yerleşik paketleme sisteminde kullanılan polistiren atığ 1 olan polistiren köpügün bir maliyet getirmemesi, ayrıca, bu üç adsorban malzemelerin ortak özelliklerinin çevre dostu olmaları, yüksek maliyetlere mal olan petrol kirliliklerin temizlenmesinde temizleme sorbentleri olarak kullanılmalarına imkan sağlayacaktır.

Günümüzde, petrol kirliliklerinin temizlenmesinde bazı adsorban malzemeler, bez kılıflı minder, yastık vb. formda kullanılabildiği gibi bir file içerisine yerleştirilerek de kullanılabilmektedir. $\mathrm{Bu}$ malzemelerden sorbent pedlerin satış fiyatları, yoğunluklarına ve ebatlarına göre ortalama 35-130 ABD Doları, sorbent bariyerlerin satış fiyatları ise yoğunlukları, çapı ve uzunluklarına göre ortalama 78157 ABD Doları arasında değişmektedir $[14,15]$.

$\mathrm{Bu}$ çalışma sonucunda, atık straforun, atık çay lifinin ve bağlayııı olarak polistiren köpüğün bez kılıf kullanılmadan şekillendirilerek adsorbsiyon minderleri olarak tasarlanabileceği, ayrıca deney için seçilen atık adsorban malzemelerin bir file içerisine yerleştirilerek de petrol kirliliklerinin temizlenmesinde kullanılabileceği düşünülmektedir.

Çalışmada kullanılan adsorbanlardan, polistiren köpük ile çay lifinin strafora göre daha hidrofilik özellikte olduğu görülmüştür. Ancak modifikasyon ve tasarım modeli ile hidrofilik özelliğinin azaltılarak, hidrofobik özelliğinin arttırılması önerilmektedir.

Yine laboratuvar ortamında yapılan küçük ölçekli yukarıdaki testler neticesinde elde edilen veriler kapsamında, gerçek bir kirlilik olayında ortamda bulunan petrol miktarının çokluğundan ötürü daha iyi sonuçlar elde edilebileceği düşünülmektedir.

\section{KAYNAKLAR (REFERENCES)}

1. Annunciado, T., R. ve ark., "Experimental investigation of various vegetable fibers as sorbent materials for oil spills", Marine Pollution Bulletin, Cilt 50, No 11, 1340-1346, 2005.
2. Reynolds, J., G. ve ark., "Hydrophobic aerogels for oil-spill cleanup-synthesis and characterization" Journal of Non-Crystalline Solids, Cilt 292, No 1, 127-137, 2001.

3. Carmody, O. ve ark., "Surface characterisation of selected sorbent materials for common hydrocarbon fuels" Surface Science, Cilt 601, No 9, 2066-2076, 2007.

4. Suni, S. ve ark., "Use of a by-product of peat excavation, cotton grass fibre, as a sorbent for oilspills" Marine Pollution Bulletin, Cilt 49, No 1112, 916-921, 2004.

5. Karakasi, O., K. ve ark., "Surface modification of high calcium fly ash for its application in oil spill clean up" Fuel, Cilt 89, No 12, 3966-3970, 2010.

6. Arbatan, T. ve ark., "Superhydrophobic and oleophilic calcium carbonate powder as a selective oil sorbent with potential use in oil spill cleanups" Chemical Engineering Journal, Cilt 166, No 2, 787-791, 2011.

7. Teas, Ch. ve ark., "Investigation of the effectiveness of absorbent materials in oil spills clean up" Desalination, Cilt 140, No 3, 259-264, 2001.

8. Kayacan, S., "Kömür ve Koklarla Sulu Çözeltilerden Boyar Maddelerin Uzaklaştırılması", Yüksek Lisans Tezi, T.C. Ankara Üniversitesi, Fen Bilimleri Enstitüsü, 2007.

9. Karaboyac1, M., "Modifiye Edilmiş Lignoselülozikler ile Ăgır Metal Adsorpsiyonu", Doktora Tezi, T.C. Süleyman Demirel Üniversitesi, Fen Bilimleri Enstitüsü, 2010.

10. Türkoğlu, S., "Sudaki Fenolik Kirleticilerin Farklı Adsorplayıcılara Adsorpsiyonu ve Katının Mikrodalga Rejenerasyonu" Yüksek Lisans Tezi, T.C. Ankara Üniversitesi, Fen Bilimleri Enstitüsü, 2010.

11. Topakoğlu, L., “İstanbul Boğazı'nda Deniz Yolu ile Petrol Taşımacılığının Çevresel Risk Değerlendirmesi', Yüksek Lisans Tezi, İstanbul Teknik Üniversitesi, Fen Bilimleri Enstitüsü, 2004.

12. Özdeş, D., Gündoğdu, A., Bulut, V. N., Duran, C., Şentürk, H. B., "Rodamin 6G boyarmaddesinin pirinç kabukları üzerine adsorpsiyonu", Dumlupınar Üniversitesi, Fen Bilimleri Enstitüsü Dergisi, Say1 28, 1302- 3055, 2009.

13. Zhang, H. ve ark., "Investigation of OMA formation and the effect of minerals" Marine Pollution Bulletin, Cilt 60, No 9, 1433-1441, 2010.

14. İnternet

AbsorbentsOnline http://www.absorbentsonline.com/booms.htm

15. İnternet : Osprey Industrial Marine http://www.ospreycontainers.co.uk/\# 
